\title{
Zinc deficiency decreases bone mineral density of rat by calmodulin-induced change in calcium metabolism
}

Qingli $\mathrm{Yu}^{1+}$, Jiali Zhaoo ${ }^{2+}$, Yanfeng Chen ${ }^{3}$, Zixiang $\mathrm{Li}^{4}$, Yongzhi Sun ${ }^{5}$, Lina Fan ${ }^{6}$, Maoqing Wang ${ }^{7, *}$, Chenghai Peng, ${ }^{8, *}$

$\dagger$ Contributed equally

1 National Key Disciplines of Nutrition and Food Hygiene, Department of Nutrition and Food Hygiene, School of Public Health, Harbin Medical University, Harbin, 150081 China; yql1284649146@163.com

2 Yiwu Maternity and Children Hospital, Yiwu, Zhejiang, China; zhaojiali320@163.com

3 Public Health Inspection and Testing Institute, Heilongjiang Provincial Center for Disease Control and Prevention, Harbin, China; 78464531@qq.com

4 National Key Disciplines of Nutrition and Food Hygiene, Department of Nutrition and Food Hygiene, School of Public Health, Harbin Medical University, Harbin, 150081 China; lizixiangd1994@163.com

5 National Key Disciplines of Nutrition and Food Hygiene, Department of Nutrition and Food Hygiene, School of Public Health, Harbin Medical University, Harbin, 150081 China; yfyxsyz@163.com

6 National Key Disciplines of Nutrition and Food Hygiene, Department of Nutrition and Food Hygiene, School of Public Health, Harbin Medical University, Harbin, 150081 China; pikaqiu_0612@163.com

7,* Dr. Maoqing Wang, Ph.D.

National Key Disciplines of Nutrition and Food Hygiene, Department of Nutrition and Food Hygiene, School of Public Health, Harbin Medical University, Harbin, 150081 China

Fax: (86)-451-87502885, Tel: (86)-451-87502876

E-mail:wang_maoqing@126.com

8,* Dr. Chenghai Peng, Ph.D.

Department of Emergency Medicine, The Forth Affiliated Hospital, Harbin Medical University, Harbin, 150081 China

Tel: (86)-451-82576886

E-mail: pengch1900@163.com

Abstract: (1) Background: Zinc deficiency decreases bone mineral density (BMD), but it is not known whether decreased BMD is a result of altered calcium absorption, excretion, and/or tissue distribution. To identified the associations between zinc deficiency, calcium metabolism and decreased BMD. (2) Methods: we performed two zinc deficiency experiments. In the first experiment, male rats (5-week-old) were fed a low zinc diet for four weeks. We measured serum zinc, alkaline phosphatase, Ca2+, osteocalcin, calcitonin, parathyroid hormone (PTH), calcium concentrations in feces and urine, BMD, and femur bone length and weight. In the second experiment, male rats (3-week-old) were fed a low zinc diet for five weeks. In addition to the aforesaid indicators, we measured the concentrations of zinc, total calcium, and calmodulin in multiple tissues. (3) Results: In both experiments, serum zinc, alkaline phosphatase, fecal and urine calcium, BMD, and bone weight of the low zinc diet group (LZG) were reduced compared with the normal zinc diet group (NZG)and pair-fed group (PZG); PTH increased significantly. Serum $\mathrm{Ca} 2+$, osteocalcin, and calcitonin concentrations were unchanged and not associated with decreased BMD. In the second experiment, zinc concentrations were reduced in serum, skeletal muscle, feces, and urine of LZG animals compared with NZG and PZG. Calmodulin in serum and 
bioRxiv preprint doi: https://doi.org/10.1101/2020.06.09.143396; this version posted June 10, 2020. The copyright holder for this preprint (which was not certified by peer review) is the author/funder. All rights reserved. No reuse allowed without permission.

skeletal muscle of the LZG group was decreased. Zinc deficiency increased total calcium concentrations in serum and skeletal muscle by promoting a decrease in calmodulin. To maintain blood $\mathrm{Ca} 2+$ balance, elevated PTH increased calcium reabsorption, reduced calcium excretion, stimulated bone resorption, mobilized bone calcium, and decreased BMD. (4) Conclusions: Decreased calmodulin and increased PTH induced by zinc deficiency altered calcium tissue distribution and decreased BMD of rat.

Keywords: bone mineral density; calmodulin; calcium; zinc deficiency

\section{Introduction}

Zinc is an essential element for growth of human and animals. Zinc is also an important mineral for the growth, development, and maintenance of bone and bone mineral density (BMD) [1-3]. Bone growth retardation and decreased BMD have been associated with zinc deficiency [4-7] in growing animals [8,9] and in infants[10], children and adolescents[5,11,12]. Zinc functions in bone metabolism by stimulating osteoblastic bone formation and inhibiting osteoclastic bone resorption [13,14]. Zinc supplementation prevents the bone loss and decreased BMD induced by various bone disorders [1,15-17]. However, it is not known mechanistically how zinc deficiency causes decreased BMD.

Calcium is directly related to bone development and metabolism. Adequate calcium intake is essential for the maintenance of bone health and normal BMD. Chronic calcium deficiency is a key cause of osteopenia and osteoporosis (decreased BMD). Calcium and zinc have antagonistic actions in a variety of systems [18]. Calcium is required for many types of cellular activation, whereas zinc tends to be a cellular inhibitor. Calmodulin is a ubiquitous regulator involved in many calcium-mediated processes. Calmodulin is activated by calcium and inhibited by zinc deficiency $[19,20]$. Calmodulin inhibition by zinc deficiency provides a rational molecular mechanism for zinc's antagonism of calcium effects [21,22]. A defect in calcium channels was the first limiting biochemical defect found for zinc deficiency [23,24]. Zinc deficiency decreases calcium excretion [25] and increases calcium retention[26], which, in turn, increases calcium concentrations in blood cells, platelets, and tissues. Therefore, zinc is required for normal calcium metabolism[27]. In view of this fact, we speculated that decreased BMD is closely related to changes in calcium and calmodulin induced by zinc deficiency. This proposed relationship has not been investigated.

To identified the associations between zinc deficiency, calcium metabolism and decreased BMD, we performed two low zinc diet experiments with rats. First, we measured the concentrations of calcium in serum, feces, and urine, and quantitated key enzymes and hormones involved in calcium metabolism, such as parathyroid hormone (PTH), alkaline phosphatase (ALP), osteocalcin, calcitonin, and calmodulin. Then, we assessed overall calcium metabolism in zinc-deficient rats, including absorption, excretion, mobilization, and distribution, to explain the function of zinc in decreased BMD. We found that zinc deficiency decreased calmodulin, it increased PTH, which altered calcium metabolism, especially calcium tissue distribution, and zinc deficiency decreased BMD.

\section{Materials and Methods}

\section{Animal experiments}

For the first experiment, 45 male Wistar rats (5-week-old, 110-130 g) were purchased from Beijing Vital River Laboratory Animal Technology Co., Ltd and housed individually with a 12-h light/dark cycle. The room temperature was controlled at $24 \pm 1{ }^{\circ} \mathrm{C}$ and the relative humidity was $50 \% \pm 5 \%$. After one week of adaptive feeding, the rats were randomly divided into three groups: normal zinc diet group, NZG, low zinc diet group, LZG, and pair-fed zinc group, PZG. The standard diet was based on the AIN-93G diet (American Institute of Nutrition) with dried egg white as the protein source from Beijing KeAoLiXie Animal Food co., LTD, China[26]. The zinc content in the normal and low zinc diet was 30 and $10 \mathrm{mg} / \mathrm{kg}$, respectively. PZG animals were fed 
bioRxiv preprint doi: https://doi.org/10.1101/2020.06.09.143396; this version posted June 10, 2020. The copyright holder for this preprint (which was not certified by peer review) is the author/funder. All rights reserved. No reuse allowed without permission.

with normal zinc diet ( $30 \mathrm{mg} / \mathrm{kg}$ zinc) and the food intake was the mean intake of the LZG. Body weight and food intake were measured at regular intervals. After the 4-week feeding period, all rats were fasted for 12 hours. Then, the animals were anesthetized by intraperitoneal injection of $10 \%$ chloral hydrate solution $(0.3 \mathrm{ml} / \mathrm{kg}$ body weight). Blood was collected from the abdominal aorta and allowed to stand at room temperature for 2 hours. After centrifugation at $(835 \mathrm{x} \mathrm{g})$ for 10 minutes, the serum was separated and frozen at $-80^{\circ} \mathrm{C}$. Urine and fecal samples were collected in metabolic cages with a sharp bottom funnel (see reference[26] for collection details). The left femur was dissected from muscle tissue, and femoral lengths and weights were measured.

In a second experiment, 3-week-old male rats $(n=45)$ were fed for five weeks, and all other conditions were the same as in the first experiment. In addition to the foregoing samples, heart, skeletal muscle, kidney, and testicles were collected, washed with isotonic saline, weighed, and stored at $-80{ }^{\circ} \mathrm{C}$. The Ethics Committee of Harbin Medical University approved these animal experiments.

\section{Determination of serum biochemical indicators, calcium, calmodulin, and BMD}

Ionized zinc and calcium in serum were measured by a colorimetric method (Sigma-Aldrich Trading Co., Ltd., Shanghai). BMD was measured with a dual X-ray energy bone densitometer (Norland XR-36 DEXA System, Cooper Surgical, Trumball, CT, USA) in the Second Affiliated Hospital of Harbin Medical University China.

ELISA assays (Summers Biomedical Products Co., Ltd., Beijing) were used to measure PTH, ALP, osteocalcin, calcitonin, and calmodulin in serum and tissues. Inductively coupled plasma mass spectrometry (ICP-MS) was used to measure total calcium and zinc concentrations in serum, feces, urine, liver, heart, skeletal muscle, kidney, and testis, as described[26].

\section{Statistical Analysis}

All data were expressed as mean \pm SD. Differences between groups were analyzed by an independent $t$ test and ANOVA test using SPSS software (version 17.0, Chicago, IL, USA). A two-tailed value of $\mathrm{P}<0.05$ was considered statistically significant.

\section{Results}

\section{Body weight and food intake}

As shown in Figure 1A and 1B, body weights of LZG animals from the third week in the first experiment and from the second week in the second experiment were lower than weights of NZG and PZG animals ( $\mathrm{P}<0.05)$. Food intake of LZG was significantly lower than NZG and PZG (P $<0.05)$. In both experiments, there were significant decreases in serum zinc concentration in LZG compared with NZG and PZG $(\mathrm{P}<0.05)$. We did not detect any significant differences in serum zinc between NZG and PZG in either experiment $(P>0.05)$.

\section{Femoral BMD, length, weight and serum Ca2+ concentration}

In both experiments, femoral BMD and weights of LZG were lower than those of NZG and PZG ( $\mathrm{P}<0.05$; Figure 2). The femoral lengths in the first experiment were not statistically different between the three groups $(P>0.05)$, whereas the femoral lengths of LZG were significantly shorter than those of NZG and PZG in the second experiment $(\mathrm{P}<0.05)$. We did not find any significant differences in BMD, femoral length, or weight between NZG and PZG in both experiments ( $P>0.05)$. Lastly, there were no statistical differences in serum $\mathrm{Ca} 2+$ concentrations between the three groups in both experiments ( $P>0.05$; Figure 2$)$. 

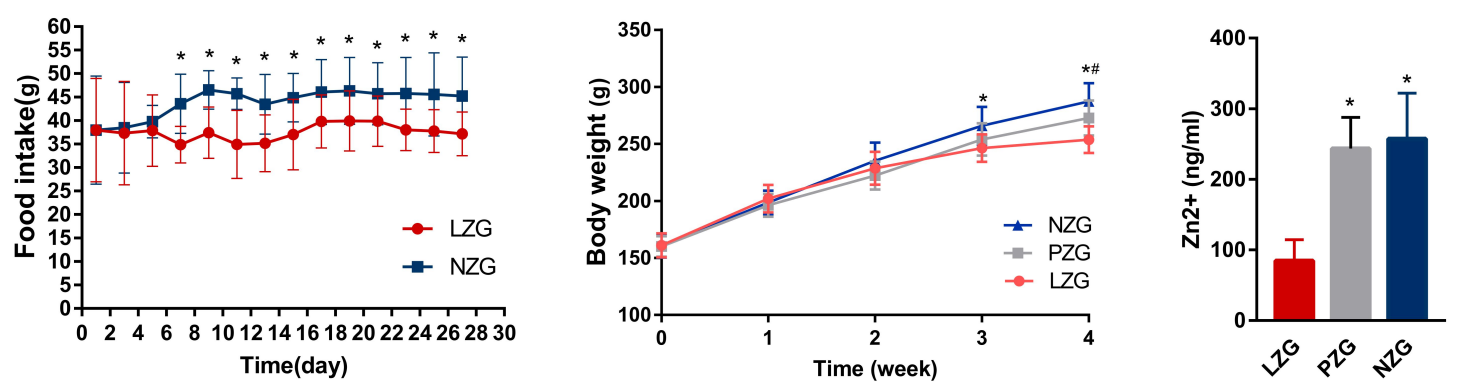

A

$\mathbf{B}$
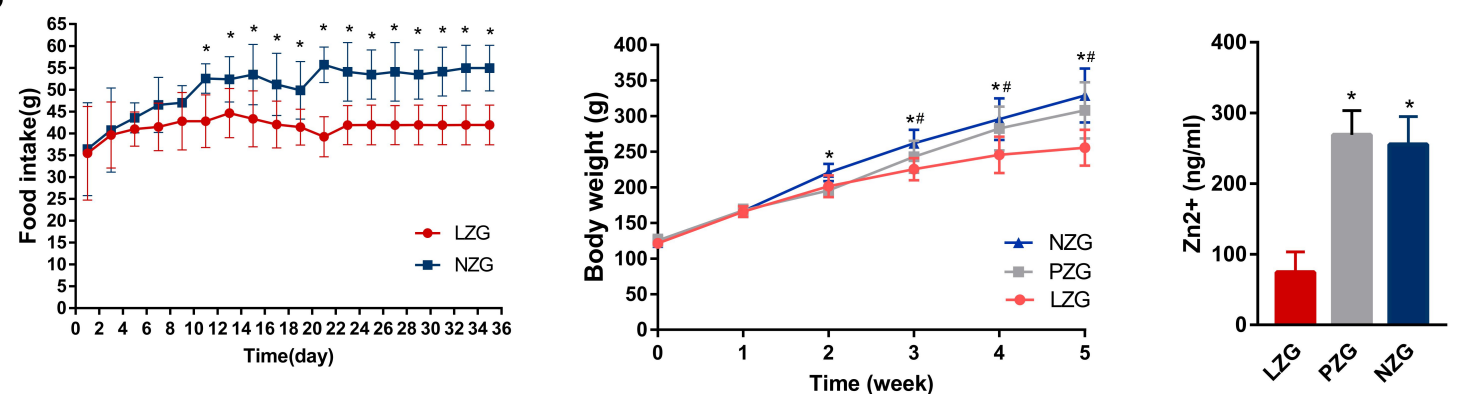

Figure-1 Food intake, body weight, and serum zinc concentration in two experiments $A$ : the first experiment, B: the second experiment. ${ }^{*} \mathrm{P}<0.05$, LZG vs NZG and PZG, \#, P<0.05, NZG vs PZG

A

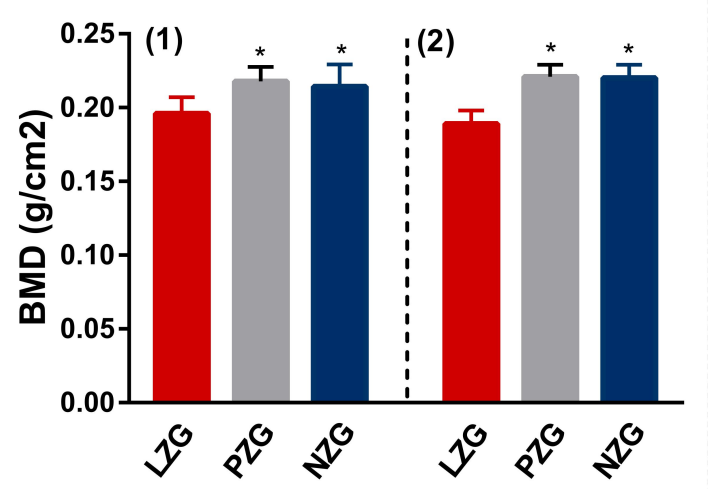

C

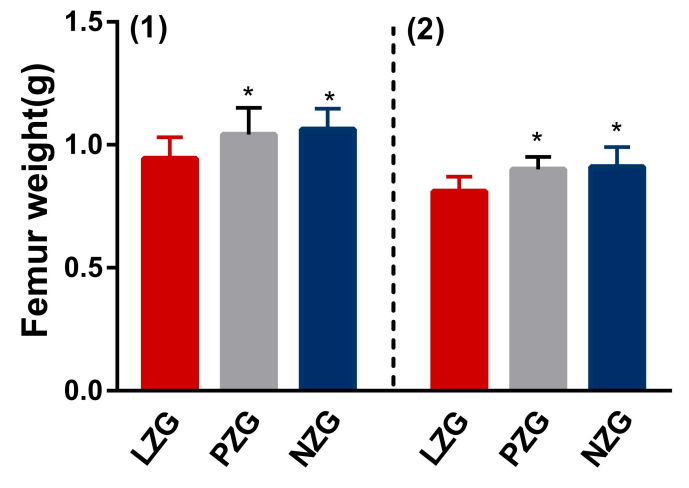

B

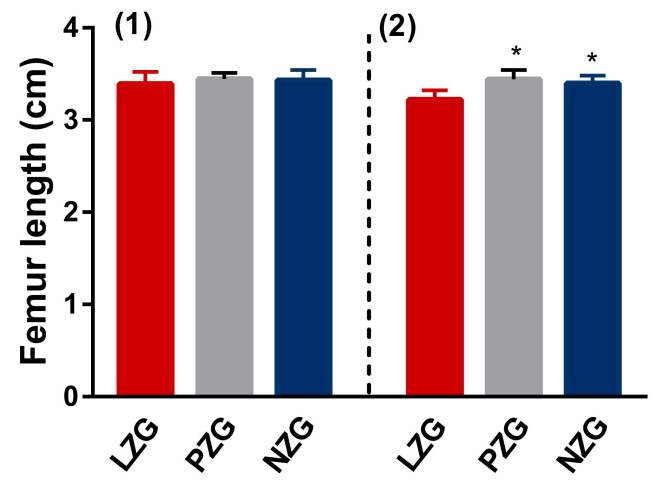

D

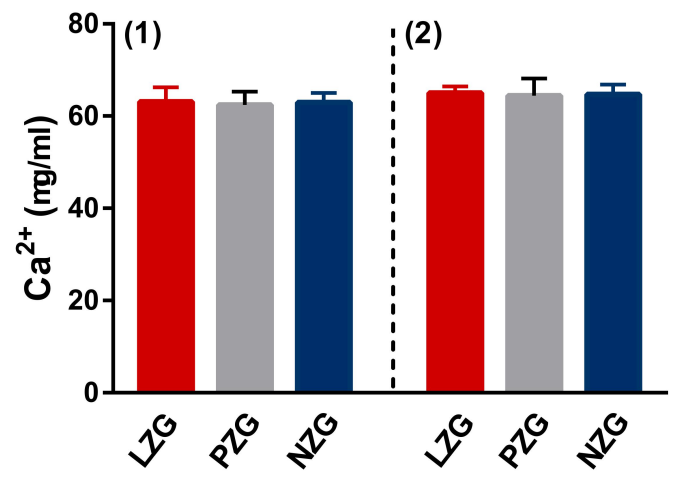

Figure-2 Femoral length, weight, BMD and serum Ca2+ concentration in two experiments (1): the first experiment, (2): the second experiment. A: BMD, B: femur length, C: femur weight, D: $\mathrm{Ca} 2+.{ }^{*} \mathrm{P}<0.05, \mathrm{LZG}$ vs NZG and PZG 
bioRxiv preprint doi: https://doi.org/10.1101/2020.06.09.143396; this version posted June 10, 2020. The copyright holder for this preprint (which was not certified by peer review) is the author/funder. All rights reserved. No reuse allowed without permission.

\section{Key enzymes and hormones involved in calcium metabolism}

The concentrations of decreased ALP (Figure 3A) and increased PTH (Figure 3B) were observed $(\mathrm{P}<0.05)$ in LZG compared with normal zinc diet groups $(\mathrm{P}<0.05)$ in both experiments. We did not detect any significant differences in osteocalcin (Figure 3C) and calcitonin (Figure 3D) between the three groups $(\mathrm{P}>0.05)$.

A

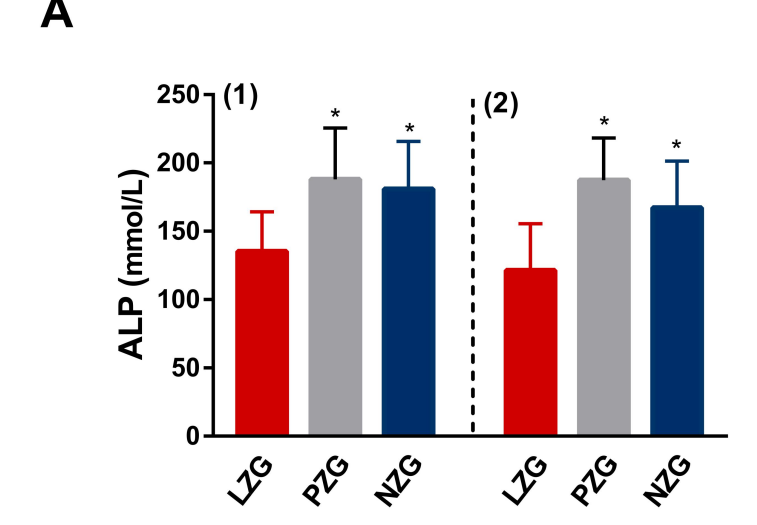

C

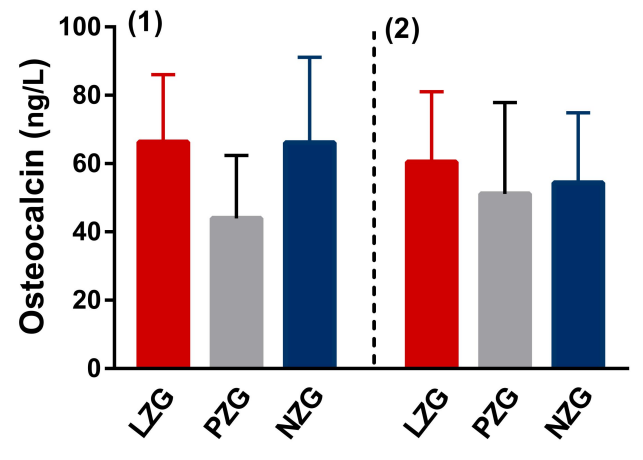

B

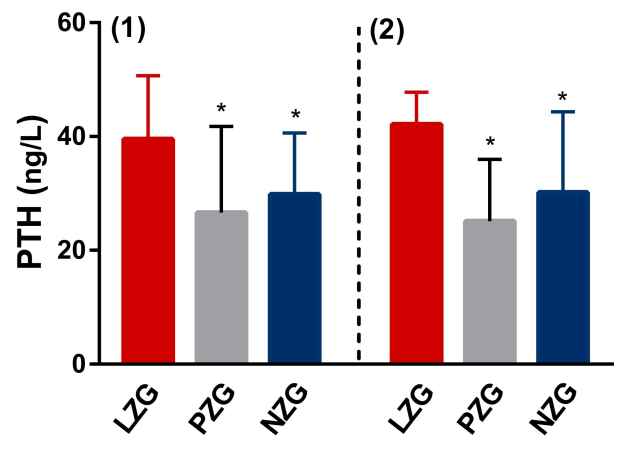

D

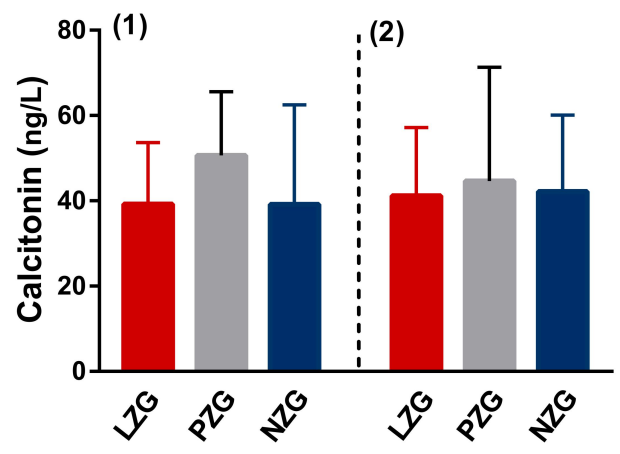

Figure-3 Concentrations of ALP, PTH, osteocalcin and calcitonin in serum in two experiments (1): the first experiment, (2): the second experiment, A: ALP, B: PTH, C: osteocalcin, D: calcitonin, ${ }^{*}<<0.05$, LZG vs NZG and PZG

\section{Total calcium concentrations in serum, feces, urine and multi tissues}

In the first experiment, we found decreases in total calcium in feces, urine, and liver, and increases in total calcium in serum in LZG compared with NZG and PZG $(P<0.05)$ in our published article[26]. We did not collect other tissues in this first experiment, thus, the concentrations of calcium in other tissues were unknown.

In the second experiment, we measured decreases in calcium in feces, urine, and liver, and increased total calcium in serum and skeletal muscle in LZG compared with NZG and PZG ( $\mathrm{P}<0.05$, Figure 4). There were no statistical differences in total calcium in heart, kidney, and testis between the three groups (Sup Figure 1). There were no differences in total calcium of serum, urine, feces, and all tissues between NZG and PZG ( $P>0.05$; Figure 4A and Sup Figure 1). Calmodulin concentrations in serum and skeletal muscle of LZG were decreased compared with NZG and PZG $(P<0.05$, Figure $4 \mathrm{~B})$, whereas there were no differences in other tissues (Sup Figure 1B). Calmodulin in all tissues was not significantly different between NZG and PZG $(\mathrm{P}>0.05)$. 
urine

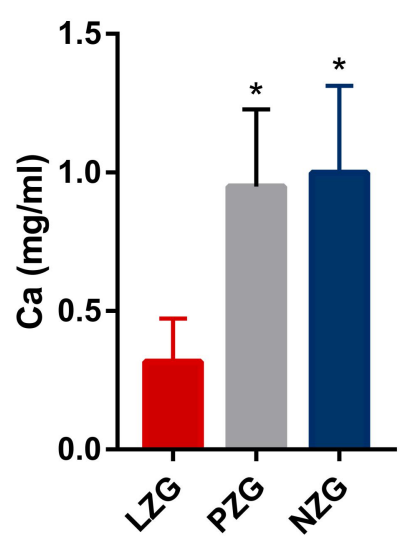

serum

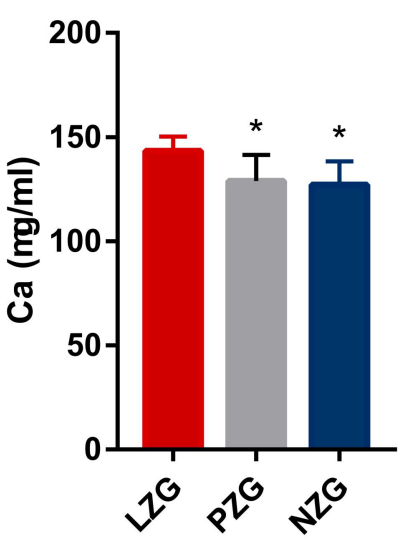

A

B

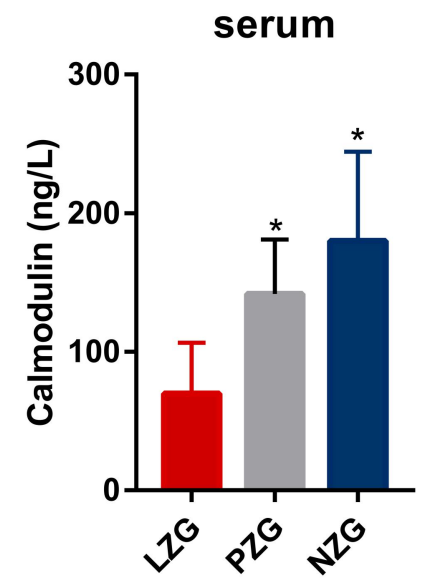

feces

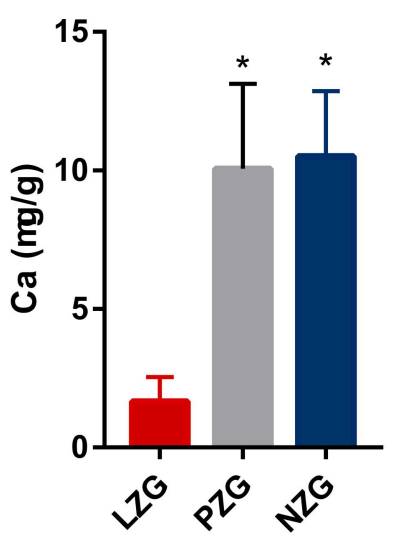

Skeletal muscle

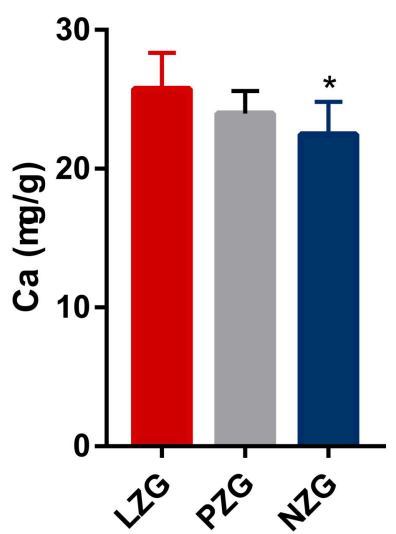

Figure-4 Concentrations of total calcium and calmodulin in different tissues in the second experiment A: Total Ca concentrations in different tissues, B: calmodulin concentrations. ${ }^{*} \mathrm{P}<0.05$, LZG vs NZG and PZG

\section{Discussion}

Calcium is directly related to skeletal development, and zinc deficiency causes decreased BMD. However, it was not known whether zinc deficiency decreases BMD by altering calcium absorption, excretion, and/or tissue distribution. By measuring the concentrations of calcium in serum, feces, 
bioRxiv preprint doi: https://doi.org/10.1101/2020.06.09.143396; this version posted June 10, 2020. The copyright holder for this preprint (which was not certified by peer review) is the author/funder. All rights reserved. No reuse allowed without permission.

urine, and various tissues, and the concentrations of calmodulin in various tissues, we identified the associations between low $\mathrm{Zn}$ intake and Ca metabolism and decreased BMD.

In both of our animal experiments, zinc deficiency all decreased BMD and femur bone weight (Figure 2). In the second experiment, due to the relatively young age of the rats and a longer feeding period, the low zinc diet affected bone development and decreased femur length. In our previous study, we found that a low calcium diet (12 weeks) decreased rat BMD[28]. However, in the present study, we found that a low zinc diet (four weeks) decreased BMD and femur length of LZG (Figure 2). Thus, zinc deficiency had a greater negative effect on BMD compared with calcium deficiency. Therefore, it was necessary to reveal the relationship between zinc deficiency and decreased BMD.

\section{Relationship between zinc deficiency, calcium metabolism and decreased BMD}

In the two experiments, we measured significant increases in PTH and decreases in ALP in LZG; the serum concentrations of calcitonin and osteocalcin were unchanged between the three groups (Figure 3). Thus, significantly increased PTH and decreased ALP were associated with decreased BMD, and calcitonin and osteocalcin were not associated with decreased BMD.

In the first experiment, we did not find changes in serum Ca2+ (Figure 2), but calcium level and calcium excretion in feces and urine of LZG (Figure 4) were reduced compared with NZG and PZG. These changes may have been related to elevated PTH. Elevated PTH increases reabsorption of calcium, decreases calcium level, and decreases calcium excretion in urine and feces. Our results suggested that zinc deficiency increased calcium reabsorption and calcium of LZG was not lost[26]. Serum Ca2+ was also not different between the three groups in the second experiments (Figure 2). There was no difference in dietary calcium intake between LZG and PZG (Figure 1). Thus, why did the BMD of LZG decrease, and where was the calcium that was lost from the femurs of LZG? Other investigators have found that zinc deficiency increased calcium retention in other tissues [19]. Therefore, we speculated that zinc deficiency increased the distribution of calcium in serum or other tissues by the combined effects of calcium-activated calmodulin and decreased BMD.

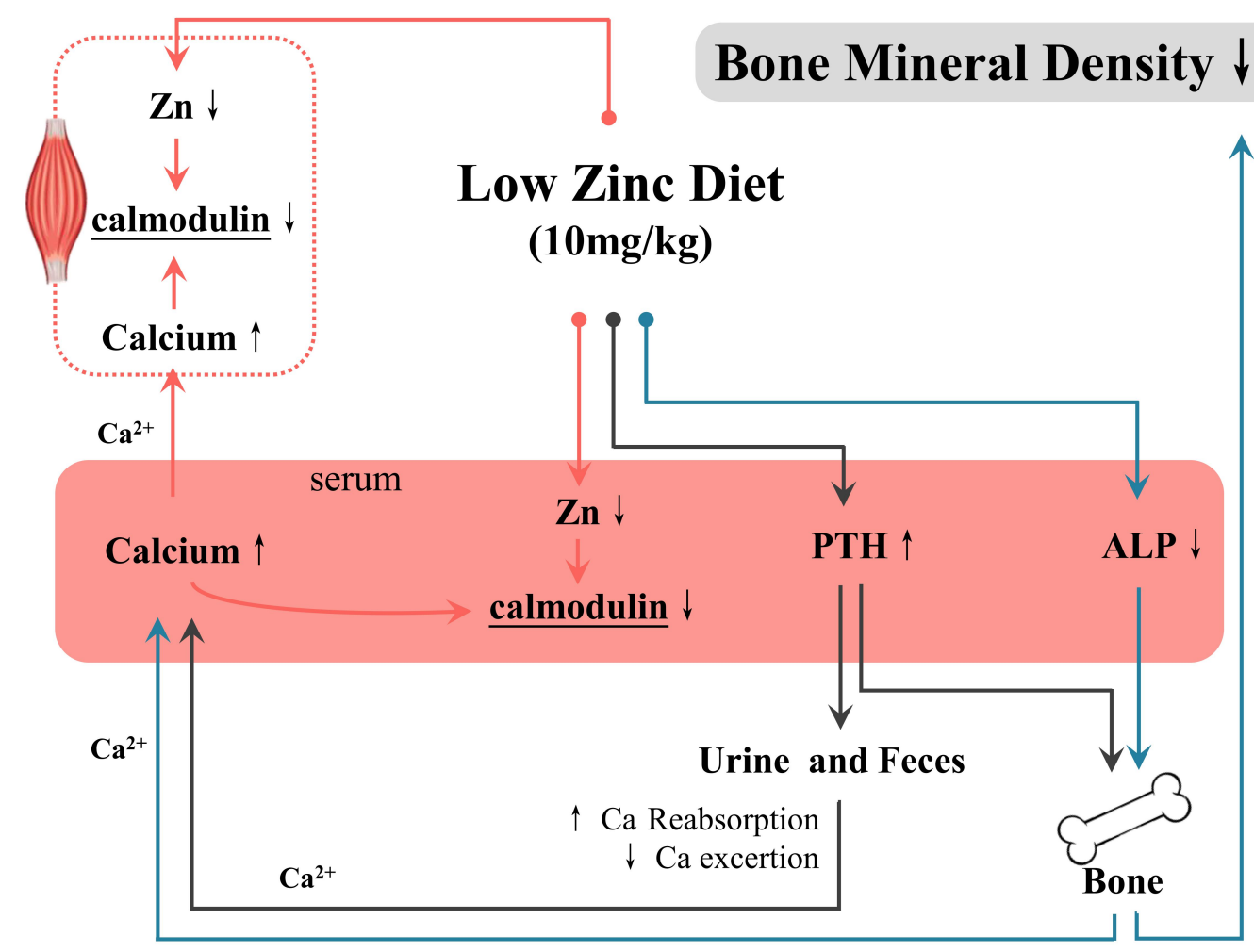

Figure 5 Relationship between zinc deficiency, altered calcium metabolism and decreased BMD $\uparrow:$ LZG vs NZG and PZG; $\downarrow$ : LZG vs NZG and PZG 
bioRxiv preprint doi: https://doi.org/10.1101/2020.06.09.143396; this version posted June 10, 2020. The copyright holder for this preprint (which was not certified by peer review) is the author/funder. All rights reserved. No reuse allowed without permission.

We tested the foregoing hypothesis in the second experiment. In addition to serum, urine, and feces, we collected various tissues and measured their concentrations of total calcium, zinc, and calmodulin to reveal the effect of zinc deficiency on calcium metabolism. We also observed decreased calcium in feces and urine of LZG. This result confirmed that calcium was not lost in zinc-deficient rats. As we expected, we found increased total calcium in serum and skeletal muscle in LZG compared with NZG and PZG (Figure $4 \mathrm{~A}$ ), and there were no changes in other tissues, including heart, kidney, and testis (Sup Figure1). These results further confirmed our speculation that zinc deficiency redistributed calcium and increased the concentrations of total calcium in serum and skeletal muscle. The calcium redistribution of LZG correlated with decreased BMD .

Zinc and calcium exhibit antagonistic actions in metabolism. Zinc deficiency inhibits calmodulin activity, whereas calcium increases calmodulin activity. In the second experiment, decreased zinc (Sup Table 1) and decreased calmodulin (Figure 4B) were both observed in LZG compared with NZG. Without sufficient zinc, more calcium in blood and skeletal muscle was needed to increase or maintain the activity of calmodulin. To increase calcium in serum and skeletal muscle, elevated PTH promoted calcium reabsorption and inhibited calcium excretion in urine and feces (Figure 5). Therefore, compared with NZG, we observed decreased calcium concentrations and excretion in urine and feces of LZG in both experiments (Figure 4).

Calcium concentrations in the blood and fluid that surround cells are tightly controlled to preserve normal physiological function. The skeleton is a reserve of calcium which is drawn upon to maintain adequate serum calcium when calcium intake is limited. Elevated PTH stimulates bone resorption and release of bone calcium for restoring serum calcium concentration, a process that ultimately causes a decrease in BMD[29] (Figure 5). If LZG had continued to be fed a low zinc diet, the calcium deficiency of rat would have been more severe. But, we can not explain the reason of decreased Ca in liver in our study.

Several studies found that serum zinc was associated with BMD among children 0-5 years-old and adolescent girls[5,11,12]. On the other hands, zinc supplementation can improve bone density of young adults[30]. However, the above studies did not clearly reveal the relationship between zinc deficiency and decreased BMD in children and adolescents. Our study provided a foundation for tackling the mechanism of the low zinc mediated impairment of normal Ca metabolism. Therefore, we recommend that children and adolescents should monitor the nutritional status of zinc because zinc helps to resist the shift in distribution of calcium and maintains their bone health.

\section{Conclusions}

Zinc deficiency reduced calmodulin in serum and skeletal muscle and increased total calcium concentrations in these sources. To maintain blood calcium balance, elevated PTH increased calcium absorption, decreased excretion, and mobilized bone calcium, eventually leading to decreased BMD of rat. Children and adolescents must ensure proper zinc intake for maintaining their bone health.

Supplementary Materials: Figure S1: The concentrations of total calcium and calmodulin of different tissues in the second experiment, Table S1: The concentrations of Zinc in 8 tissues of rats

Supplemental Table-1 The concentrations of Zinc in 8 tissues of rats

\begin{tabular}{cccc}
\hline & LZG & PZG & NZG \\
\hline Feces $(\mu \mathrm{g} / \mathrm{g})$ & $23.23 \pm 6.03$ & $247.68 \pm 19.79^{*}$ & $253.31 \pm 36.17^{*}$ \\
Urine $(\mu \mathrm{g} / \mathrm{ml})$ & $4.56 \pm 1.21$ & $9.34 \pm 2.66^{*}$ & $8.16 \pm 2.72^{*}$ \\
Serum $(\mu \mathrm{g} / \mathrm{ml})$ & $1.89 \pm 0.09$ & $2.26 \pm 0.33^{*}$ & $2.19 \pm 0.44^{*}$ \\
Skeletal muscle $(\mu \mathrm{g} / \mathrm{g})$ & $14.82 \pm 2.08$ & $15.61 \pm 1.62$ & $18.72 \pm 3.49^{*}$ \\
Liver $(\mu \mathrm{g} / \mathrm{g})$ & $47.26 \pm 2.89$ & $57.70 \pm 4.65^{*}$ & $60.22 \pm 5.46^{*}$ \\
Kidney $(\mu \mathrm{g} / \mathrm{g})$ & $23.10 \pm 1.55$ & $25.55 \pm 3.33$ & $27.15 \pm 2.72$ \\
Testis $(\mu \mathrm{g} / \mathrm{g})$ & $19.77 \pm 2.46$ & $10.75 \pm 1.89^{*}$ & $13.84 \pm 2.44^{*}$
\end{tabular}




\begin{tabular}{crrr} 
Heart $(\mu \mathrm{g} / \mathrm{g})$ & $19.68 \pm 1.50$ & $18.86 \pm 1.79$ & $20.43 \pm 1.25$ \\
\hline$*: \mathrm{P}<0.05$ LZG vs NZG and PZG.
\end{tabular}
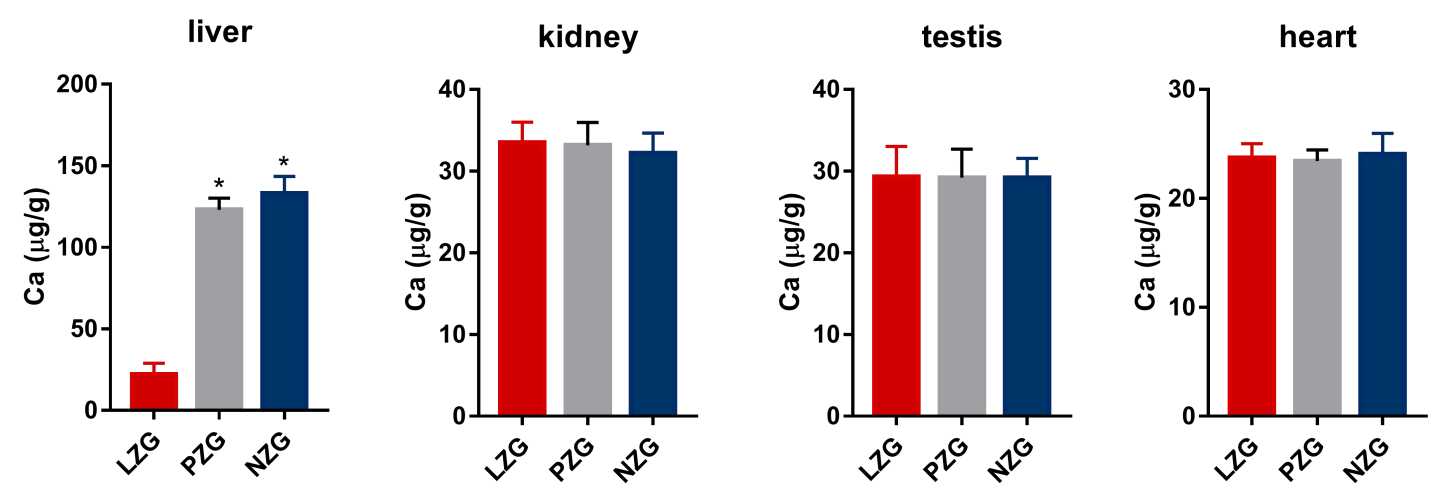

A
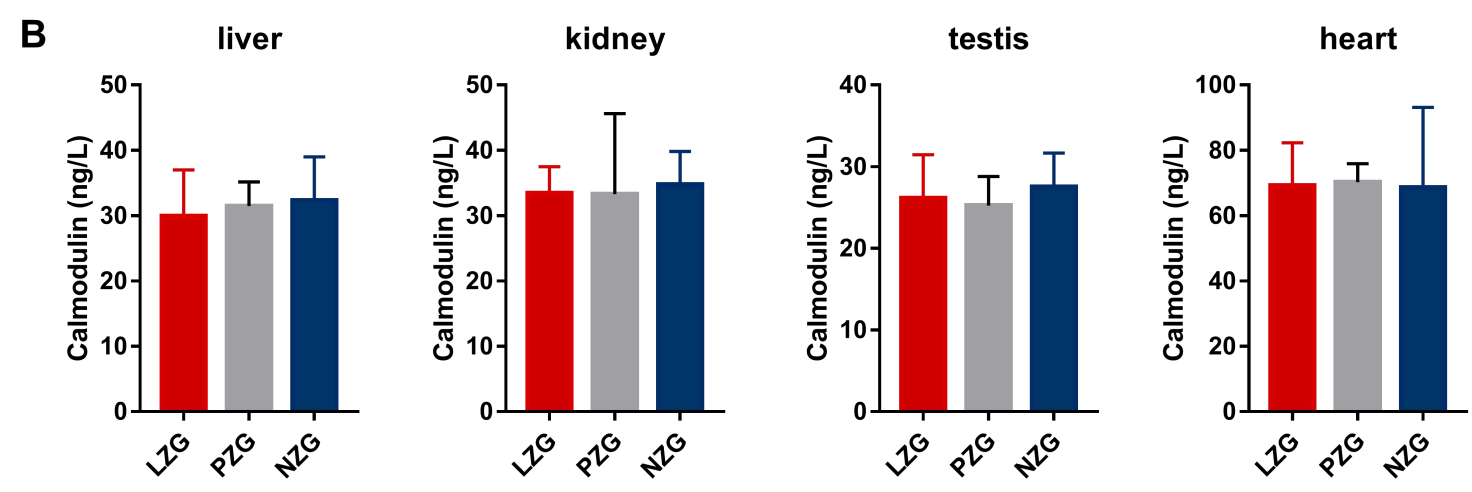

Supplemental figure-1 The concentrations of total calcium and calmodulin of different tissues in the second experiment A: Total calcium, B: calmodulin.

Author Contributions: Maoqing Wang and Chenghai Peng contributed to the study's conception and design. Qingli $\mathrm{Yu}$ and Jiali Zhao drafted the manuscript. Qingli Yu performed data analysis and interpretation. Zixiang Li, Yongzhi Sun and Lina Fan performed animal experiments and data collection. Yanfeng Chen measured element concentrations by ICP-MS. The final draft was read and approved by all the authors.

Funding: This work was supported by grants from National Nature Science Foundation of China (81573147 and 81973036).

Acknowledgments: The authors thank AiMi Academic Services (www.aimieditor.com) for English language editing and review services.

Conflicts of Interest: All authors have declared that no conflict of interest exists.

\section{References}

1. Yamaguchi, M. Role of zinc in bone formation and bone resorption. Journal of Trace Elements in Experimental Medicine 1998, 11, 119-135.

2. Zheng, J.; Mao, X.; Ling, J.; He, Q.; Quan, J. Low serum levels of zinc, copper, and iron as risk factors for osteoporosis: a meta-analysis. Biol Trace Elem Res 2014, 160, 15-23, doi:10.1007/s12011-014-0031-7.

3. Yamaguchi, M. Nutritional Zinc Plays a Pivotal Role in Bone Health and Osteoporosis Prevention. Edorium Journal of Nutrition $\mathcal{E}$ Dietetics 2015, 1-8.

4. Hyun, T.H.; Elizabeth, B.-C.; B, M.D. Zinc intakes and plasma concentrations in men with 
osteoporosis: the Rancho Bernardo Study. American Journal of Clinical Nutrition 2004, 80, 715-721.

5. Bouglé, D.L.; Sabatier, J.P.; Guaydier-Souquières, G.; Guillon-Metz, F.; Laroche, D.; Jauzac, P.; Bureau, F. Zinc status and bone mineralisation in adolescent girls. J Trace Elem Med Biol 2004, 18, 17-21, doi:10.1016/j.jtemb.2004.03.001.

6. Grant, E.C.G. Osteoporosis caused by zinc and magnesium deficiencies. 2017.

7. Elmståhl, S.; Gullberg, B.; Janzon, L.; Johnell, O.; Elmståhl, B. Increased incidence of fractures in middle-aged and elderly men with low intakes of phosphorus and zinc. Osteoporos Int 1998, 8, 333-340, doi:10.1007/s001980050072.

8. Giugliano, R.; Millward, D.J. Growth and zinc homeostasis in the severely Zn-deficient rat. British Journal of Nutrition 1984, 52, 545-560.

9. Ryz, N.R.; Weiler, H.A.; Taylor, C.G. Zinc deficiency reduces bone mineral density in the spine of young adult rats: a pilot study. Ann Nutr Metab 2009, 54, 218-226, doi:10.1159/000224627.

10. Walravens, P.A.; Hambidge, K.M.; Koepfer, D.M. Zinc supplementation in infants with a nutritional pattern of failure to thrive: A double-blind, controlled study. Pediatrics 1989, 83, 532-538.

11. Xiu-Lan, M.A. Relationship between bone mineral density and serum zinc,iron,and lead among children 0-5 years-old. Chinese Journal of Healthy Birth \& Child Care 2010.

12. Bekheirnia, M.R.; Shamshirsaz, A.A.; Kamgar, M.; Bouzari, N.; Erfanzadeh, G.; Pourzahedgilani, N.; Tabatabaie, S.M.; Abdollah Shamshirsaz, A.; Kimiagar, M.; Ezzati, F., et al. Serum zinc and its relation to bone mineral density in beta-thalassemic adolescents. Biol Trace Elem Res 2004, 97, 215-224, doi:10.1385/bter:97:3:215.

13. Yamaguchi, M.; Oishi, H.; Suketa, Y. Stimulatory Effect of Zinc on Bone Formation in Tissue Culture. Biochemical Pharmacology 1987, 36, 4007-4012.

14. Hsieh, H.S.; Navia, J.M. Zinc deficiency and bone formation in guinea pig alveolar implants. Journal of Nutrition 1980, 110, 1581-1588.

15. Ronaghy, H.A.; Reinhold, J.G.; Mahloudji, M.; Ghavami, P.; Fox, M.R.; Halsted, J.A. Zinc supplementation of malnourished schoolboys in Iran: increased growth and other effects. 1974, 27, 112-121.

16. Lowe, N.M.; Fraser, W.D.; Jackson, M.J. Is there a potential therapeutic value of copper and zinc for osteoporosis? Proceedings of the Nutrition Society 2002, 61, 181-185.

17. Yamaguchi, M. Role of nutritional zinc in the prevention of osteoporosis. Mol Cell Biochem 2010, 338, 241-254, doi:10.1007/s11010-009-0358-0.

18. Brewer, G.J. Calmodulin, zinc, and calcium in cellular and membrane regulation: An interpretive review. American Journal of Hematology 1980, 8, 231-248.

19. Roth, H.P.; Kirchgessner, M. Calmodulin, zinc and calcium concentration in tissues of zinc- and calcium-deficient rats. Journal of Trace Elements $\mathcal{E}$ Electrolytes in Health $\mathcal{E}$ Disease 1988, 2, 73-78.

20. Law, J.S.; Mcbride, S.A.; Graham, S.; Nelson, N.R.; Henkin, R.I. Zinc deficiency decreases the activity of calmodulin regulated cyclic nucleotide phosphodiesterases in vivo in selected rat tissues. Biological Trace Element Research 1988, 16, 221-226.

21. Brewer, G.J.; Aster, J.C.; Knutsen, C.A.; Kruckeberg, W.C. Zinc inhibition of calmodulin: a proposed molecular mechanism of zinc action on cellular functions. Am J Hematol 1979, 7, 53-60, doi:10.1002/ajh.2830070107.

22. Hurley, L.S.; Keen, C.L.; Bo, L.; Rucker, R.B. Trace Elements in Man and Animals 6; Plenum Press: 1988. 
23. O'Dell, B.L. Role of zinc in plasma membrane function. Journal of Nutrition 2000, 130, $1432 S$.

24. Bettger, W.J.; O'Dell, B.L. Physiological roles of zinc in the plasma membrane of mammalian cells. J.nutr.biochem 1993, 4, 194-207.

25. Nielsen, F.H. Marginal zinc deficiency increases magnesium retention and impairs calcium utilization in rats. Biol Trace Elem Res 2009, 128, 220-231, doi:10.1007/s12011-008-8268-7.

26. Yu, Q.; Sun, X.; Zhao, J.; Zhao, L.; Chen, Y.; Fan, L.; Li, Z.; Sun, Y.; Wang, M.; Wang, F. The effects of zinc deficiency on homeostasis of twelve minerals and trace elements in the serum, feces, urine and liver of rats. Nutrition \& metabolism 2019, 16, 73, doi:10.1186/s12986-019-0395-y.

27. Hurley, L.S.; Gowan, J.; Milhaud, G. Calcium Metabolism in Manganese-Deficient and Zinc-Deficient Rats. Proc Soc Exp Biol Med 1969, 130, 856-860.

28. Wang, M.; Yang, X.; Wang, F.; Li, R.; Ning, H.; Na, L.; Huang, Y.; Song, Y.; Liu, L.; Pan, H., et al. Calcium-deficiency assessment and biomarker identification by an integrated urinary metabonomics analysis. BMC medicine 2013, 11, 86, doi:10.1186/1741-7015-11-86.

29. Suzuki, T.; Kajita, Y.; Katsumata, S.; Matsuzaki, H.; Suzuki, K. Zinc Deficiency Increases Serum Concentrations of Parathyroid Hormone through a Decrease in Serum Calcium and Induces Bone Fragility in Rats. J Nutr Sci Vitaminol (Tokyo) 2015, 61, 382-390, doi:10.3177/jnsv.61.382.

30. Fung, E.B.; Kwiatkowski, J.L.; Huang, J.N.; Gildengorin, G.; King, J.C.; Vichinsky, E.P. Zinc supplementation improves bone density in patients with thalassemia: a double-blind, randomized, placebo-controlled trial. Am J Clin Nutr 2013, 98, 960-971, doi:10.3945/ajcn.112.049221. 